\title{
Assessing psychometric reliability and validity of Technology Acceptance Model (TAM) among faculty members at Shahid Beheshti University
}

\author{
Mohsen Ameri Shahrabi ${ }^{a^{*}, A}$ Azam Ahaninjan ${ }^{b}$, Hamid Nourbakhsh ${ }^{c}$, Morteza Amani Ashlubolagh $^{\mathrm{d}}$, \\ Jamal Abdolmaleki ${ }^{\mathrm{e}}$ and Maboud Mohamadi ${ }^{\mathrm{f}}$
}

\begin{tabular}{l}
${ }^{a}$ Faculty member, Department of Engish and Management, Islamic Azad University, Naragh Branch, Naragh, Iran \\
${ }^{b} M$. A. in Information technology \& Expert of Information technology in Iran supreme Audit Court, Tehran, Iran \\
${ }^{c} M A$ in Accountimg, Senior Auditor in Iran supreme Audit Court, Tehran, Iran \\
${ }^{d} P$ D Candidate in Educational Administration, Kharazmi University, Tehran, Iran \\
${ }^{e} P$ D Student in Educational Planning, Shahid Beheshti University, Tehran, Iran \\
${ }^{f} M A$ in Economics, Superintendent in Iran Supreme Audit Court, Tehran, Iran \\
\hline C H R O N I C L E
\end{tabular}

Article history:

Received May 9, 2013

Received in revised format

10 July 2013

Accepted 12 July 2013

Available online

July 152013

Keywords:

Technology acceptance

measurement

TAM

Confirmatory factor analysis

\begin{abstract}
This paper presents an empirical survey on understanding the content validity and reliability of technology acceptance measurement (TAM) among 278 university professors who worked for university of Shahid Beheshti located in city of Tehran Iran. We use a questionnaire consists of 37 different questions in five categories including perceived usefulness, perceived ease of use, attitude towards the use of technology and operating plan in Likert scale. The proposed study uses first-order confirmatory factor analysis for validity of the questionnaire and Cronbach alpha is employed for measuring the reliability of the questionnaire. The results have confirmed that TAM questionnaire maintains sufficient content validity and reliability. In other words, The measures were refined and stream-lined, resulting in two six-item scales with reliabilities of 0.89 for usefulness and 0.87 for ease of use.
\end{abstract}

\section{Introduction}

Valid measurement scales for predicting user acceptance of information technology has become popular during the past two decades. There different techniques for measuring technology acceptance but many of them are not fully integrated, and their relationship to system usage is unknown. Davis (1989) developed and validated new scales for two specific variables, perceived usefulness and perceived ease of implementation hypothesized to be basic determinants of user acceptance. He used the definitions for these two variables to develop scale items pretested for content validity and then tested for reliability and construct validity in two studies and four application programs. 
Computer systems are not able to improve organizational performance if they aren't fully implemented and in many cases, resistance to end-user systems by managers and professionals creates some problem. To better forecast, describe, and increase user acceptance, there is a need to better understand why people accept or reject computers.

Davis et al. (1989) described the capability to forecast peoples' computer acceptance from a measure of their will, and the capability to describe their intentions in terms of their behaviours, subjective norms, perceived usefulness, perceived ease of use, and associated variables. In their survey, perceived usefulness strongly affected peoples' intentions, describing more than half of the variance in intentions at the end of 14 weeks. Perceived ease of implementation maintained a small but significant impact on intentions as well, although this impact subsided over time. Attitudes only partially mediated the impacts of these beliefs on intentions. Subjective norms had no impacts on intentions. These results recommended the possibility of simple but powerful techniques of the determinants of user acceptance, with practical value for assessing systems.

Gardner and Amoroso (2004) reviewed different studies using TAM to create a modified model and instrument to investigate the acceptance of Internet technology by consumers. They investigated the relationships between the TAM constructs in some of the research that purports to describe the variance in the acceptance of various information technologies. Based on the empirical research implementing the technology assessment model, they presented a modified TAM for the acceptance of Internet-based technologies by consumers. The original constructs (beliefs, attitudes, behavior and use) were kept from the TAM while the literature suggested gender, experience, complexity, and voluntariness to be useful antecedents for predicting perceived usefulness, perceived ease of use and behavioral intent to implement. Hypotheses were studied in this study associated with the theoretical relationships between constructs and antecedents.

Information systems (IS) implementation is normally expensive and in some cases may have a relatively low success rate. IS research has contributed to a better perception of this process and its outcomes. The early efforts concentrated on the determination of factors that facilitated IS implementation. It is now obvious that, for practical reasons, the factors had to be grouped into a model in a way that would facilitate analysis of IS use (Legris et al., 2003). TAM is a useful model, but has to be integrated into other techniques, which would include variables associated with both human and social change processes, and to the adoption of the innovation model (Legris et al., 2003).

Liaw and Huang (2003) performed an investigation of user attitudes toward search engines as an information retrieval tool. They reported that individual computer experience, quality of search systems, motivation, and perceptions of technology acceptance were all key factors, which influence individual feelings to implement search engines as an information retrieval tool. Liaw (2004) offered five different views of considerations, which describes why people use cyberspace. Park (2009) performed an analysis of the TAM in understanding university students' behavioral intention to use elearning.

Rose and Straub (1998) tried to predict general IT use by applying TAM to the Arabic world. Stettheimer and Cleveland (1998) presented a model for utilization of planned information technology. Thong et al. (2002) performed a survey to understand user acceptance of digital libraries by utilizing TAM. They detected three system interface characteristics, three organizational context variables, and three individual differences as critical external variables, which influence on adoption intention through perceived usefulness and perceived ease of use of the digital library. Venkatesh and Brown (2001) performed a longitudinal investigation of personal computers in homes by looking into adoption determinants and emerging challenges. 


\section{The proposed study}

In this paper, we present an empirical survey to understand the content validity and reliability of technology acceptance measurement (TAM) among 278 university professors who worked for university of Shahid Beheshti located in city of Tehran Iran. We use a questionnaire consists of 37 different questions in five categories including perceived usefulness, perceived ease of use, attitude towards the use of technology and operating plan in Likert scale.

The proposed study uses first-order confirmatory factor analysis for validity of the questionnaire and Cronbach alpha is employed for measuring the reliability of the questionnaire.

\section{The results}

The first component of the study is associated with perceived usefulness and Table 1 summarizes the results of our survey.

\section{Table 1}

The summary of t-student values on perceived usefulness

\begin{tabular}{cccccc}
\hline Question & Non-standard & Standard & Standard t & Standard error & Standard t error \\
\hline 1 & 1.25 & 0.66 & 1.25 & 11.56 & 0.018 \\
2 & 1.12 & 0.57 & 1.33 & 9.45 & 0.21 \\
3 & 1.45 & 0.71 & 1.21 & 14.89 & 0.12 \\
4 & 1.23 & 0.54 & 0.89 & 9.56 & 0.05 \\
5 & 1.89 & 0.56 & 1.22 & 8.88 & 0.11 \\
6 & 1.26 & 0.68 & 1.36 & 10.74 & 0.08 \\
7 & 1.44 & 0.52 & 1.44 & 10.17 & 0.10 \\
8 & 1.77 & 0.64 & 1.55 & 11.12 & 0.09 \\
9 & 1.66 & 0.59 & 1.57 & 12.23 & 0.11 \\
10 & 1.32 & 0.70 & 1.78 & 13.56 & 0.07 \\
\hline
\end{tabular}

As we can observe from the results of Table 1, all 10 questions yield good t-student values, which mean TAM feature is enhanced in terms of perceived usefulness. Perceived ease of use is the next TAM characteristic, which consists of eight questions summarized in Table 2.

Table 2

The summary of t-student values on perceived ease of use

\begin{tabular}{cccccc}
\hline Question & Non-standard & Standard & Standard t & Standard error & Standard t error \\
\hline 11 & 1.36 & 0.64 & 8.78 & 0.12 & 1.44 \\
12 & 1.54 & 0.58 & 11.22 & 0.14 & 1.21 \\
13 & 1.17 & 0.60 & 10.34 & 0.17 & 1.38 \\
14 & 1.08 & 0.57 & 14.21 & 0.21 & 1.42 \\
15 & 1.45 & 0.71 & 11.44 & 0.25 & 1.32 \\
16 & 1.66 & 0.68 & 9.52 & 0.05 & 1.89 \\
17 & 1.21 & 0.63 & 10.71 & 0.14 & 1.32 \\
18 & 1.09 & 0.67 & 13.10 & 0.10 & 1.36 \\
\hline
\end{tabular}

Again, all t-student values are within acceptable limit, which means TAM feature is enhanced in terms of perceived ease of use. The third question of the survey is associated with attitude towards the use of technology and Table 3 shows details of our findings, 
Table 3

The summary of t-student values on attitude towards the use of technology

\begin{tabular}{cccccc}
\hline Question & Non-standard & Standard & Standard t & Standard error & Standard t error \\
\hline 19 & 1.27 & 0.58 & 12.41 & 0.09 & 1.34 \\
20 & 1.11 & 0.62 & 13.21 & 0.12 & 1.43 \\
21 & 1.42 & 0.71 & 14.34 & 0.13 & 1.31 \\
22 & 1.31 & 0.65 & 12.32 & 0.18 & 1.38 \\
23 & 1.36 & 0.64 & 13.38 & 0.16 & 1.42 \\
24 & 1.42 & 0.62 & 10.39 & 0.09 & 1.64 \\
25 & 1.38 & 0.66 & 11.77 & 0.17 & 1.47 \\
26 & 1.45 & 0.59 & 9.12 & 0.19 & 1.22 \\
27 & 1.57 & 0.63 & 8.59 & 0.21 & 1.12 \\
\hline
\end{tabular}

One more time, we observe that all t-student statistics are significant, which means TAM feature is enhanced in terms of attitude towards the use of technology. Finally, the item is associated with intention to use and Table 4 summarizes our results.

\section{Table 4}

The summary of t-student values on attitude towards the use of technology

\begin{tabular}{cccccc}
\hline Question & Non-standard & Standard & Standard t & Standard error & Standard t error \\
\hline 28 & 1.78 & 0.61 & 10.51 & 0.12 & 1.65 \\
29 & 1.36 & 0.57 & 8.20 & 0.10 & 1.21 \\
30 & 1.61 & 0.68 & 9.87 & 0.18 & 1.81 \\
31 & 1.21 & 0.59 & 10.54 & 0.09 & 1.58 \\
32 & 1.47 & 0.60 & 11.65 & 0.14 & 1.78 \\
33 & 1.87 & 0.70 & 12.34 & 0.11 & 1.63 \\
34 & 1.42 & 0.57 & 10.36 & 0.07 & 1.23 \\
35 & 1.31 & 0.64 & 10.81 & 0.13 & 1.01 \\
36 & 1.28 & 0.58 & 12.91 & 0.16 & 1.29 \\
\hline
\end{tabular}

As we can see, the results of t-student values are statistically significant. Table 5 shows variance and standard errors for all factors.

Table 5

The summary of variance and standard errors for all factors

\begin{tabular}{lccccc}
\hline factor & $\begin{array}{c}\text { \# of } \\
\text { questions }\end{array}$ & $\begin{array}{c}\text { Explained variance } \\
\text { (R2) factor }\end{array}$ & $\begin{array}{c}\text { Explained T value for } \\
\text { variance factor }\end{array}$ & $\begin{array}{c}\text { Standard } \\
\text { error }\end{array}$ & $\begin{array}{c}\text { value } \\
\text { standard t }\end{array}$ \\
\hline Perceived usefulness & 10 & 0.33 & 29.15 & 0.09 & 1.12 \\
Perceived ease of use & 8 & 0.25 & 22.84 & 0.05 & 1.04 \\
$\begin{array}{l}\text { Attitude towards the use of } \\
\text { technology }\end{array}$ & 9 & 0.18 & 19.17 & 0.10 & 1.87 \\
Intention to use & 9 & 0.15 & 14.27 & 0.04 & 1.16 \\
\hline Total & 36 & 0.91 & 52.49 & 0.06 & 0.75 \\
\hline
\end{tabular}

The results of Table 5 show that perceived usefulness describes nearly one-third of total explained variance while perceived ease of use describes only one quarter of total variance. Attitude towards the use of technology represents $18 \%$ and intention to use shows $15 \%$ of explained variance. Next, we present covariance of factors to measure the relationships between each pair. Table 6 shows summary of our findings, 
Table 6

The summary of correlation phi ratios between each pair of factors

\begin{tabular}{|c|c|c|c|c|c|c|c|c|c|}
\hline \multirow[b]{2}{*}{ Factor } & \multicolumn{3}{|c|}{ Perceived usefulness } & \multicolumn{3}{|c|}{ Perceived ease of use } & \multicolumn{3}{|c|}{ Attitude towards the use of technology } \\
\hline & Phi & $\mathrm{t}$ & Error & Phi & $\mathrm{t}$ & Error & Phi & $\mathrm{t}$ & Error \\
\hline Perceived usefulness & - & - & - & & & & & & \\
\hline Perceived ease of use & 0.35 & 11.12 & 0.05 & - & - & - & & & \\
\hline $\begin{array}{l}\text { Attitude towards the } \\
\text { use of technology }\end{array}$ & 0.41 & 17.14 & 0.08 & 0.54 & 21.43 & 0.07 & - & - & - \\
\hline Intention to use & 0.28 & 13.58 & 0.06 & 0.31 & 10.13 & 0.10 & 0.47 & 19.18 & 0.07 \\
\hline
\end{tabular}

As we can observe from the results of Table 6, the phi values varied from 0.28 to 0.54 , which are acceptable limits. In addition, all t-student values are within acceptable limits and errors are less than $10 \%$. Therefore, we can conclude that there are good integrations among different components. Finally, we present the first-order confirmatory factor analysis for validity of the questionnaire and Table 7 demonstrates the results of our survey.

Table 7

The summary of first-order confirmatory factor analysis for validity of the questionnaire

\begin{tabular}{|c|c|c|c|c|}
\hline Row & Attribute & Value & Criteria & Result \\
\hline 1 & Chi-square & 184.17 & Level of significance $=0.05$ & Confirmed \\
\hline 2 & $\mathrm{df}$ & 135 & - & - \\
\hline 3 & Chi-Square/df & 1.36 & $<=2$ & Confirmed \\
\hline 4 & RMSEA & 0.031 & $<=0.05$ & Confirmed \\
\hline 5 & CFI & 0.91 & $>=0.90$ & Confirmed \\
\hline 6 & NFI & 0.90 & $>=0.90$ & Confirmed \\
\hline 7 & GFI & 0.92 & $>=0.90$ & Confirmed \\
\hline 8 & AGFI & 0.90 & $>=0.90$ & Confirmed \\
\hline 9 & PGFI & 0.65 & $>=0.50$ & Confirmed \\
\hline
\end{tabular}

As we can observe from the results of Table 7, all statistical observations are within acceptable limits and we can confirm the content validity of the TAM questionnaire.

Next, we examine the reliability of the questionnaire based on Cronbach alpha and the results are summarized in Table 8 as follows,

\section{Table 8}

The summary of Cronbach alpha for testing the reliability of the questionnaire

\begin{tabular}{lccc}
\hline Factor & \# of questions & Rang of questions & Cronbach alpha \\
\hline Perceived usefulness & 10 & $1-10$ & 0.91 \\
Perceived ease of use & 8 & $11-18$ & 0.87 \\
Attitude towards the use of technology & 9 & $19-27$ & 0.90 \\
Intention to use & 9 & $28-36$ & 0.86 \\
\hline Total & 36 & $1-36$ & 0.89 \\
\hline
\end{tabular}

The results of Table 8 show that all Cronbach are well above 0.90 and they are within acceptable limits and we can confirm the reliability of the overall questionnaire.

\section{Conclusion}

In this paper, we have presented an empirical survey on understanding the content validity and reliability of technology acceptance measurement (TAM) among 278 university professors who worked for university of Shahid Beheshti located in city of Tehran Iran. We have used a questionnaire consists of 37 different questions in five categories including perceived usefulness, perceived ease of use, attitude towards the use of technology and operating plan in Likert scale. The 
proposed study has implemented first-order confirmatory factor analysis for validity of the questionnaire and Cronbach alpha has been used for measuring the reliability of the questionnaire. The results have confirmed that TAM questionnaire maintains sufficient content validity and reliability.

\section{Acknowledgment}

The authors would like to thank the anonymous referees for carefully reviewing the paper and proving constructing comments on earlier version of this paper.

\section{References}

Davis, F. D. (1989). Perceived usefulness, perceived ease of use, and user acceptance of information technology. MIS quarterly, 319-340.

Davis, F. D., Bagozzi, R. P., \& Warshaw, P. R. (1989). User acceptance of computer technology: a comparison of two theoretical models. Management science, 35(8), 982-1003.

Gardner, C., \& Amoroso, D. L. (2004, January). Development of an instrument to measure the acceptance of internet technology by consumers. In System Sciences, 2004. Proceedings of the 37th Annual Hawaii International Conference on (pp. 10-pp). IEEE.

Legris, P., Ingham, J., \& Collerette, P. (2003). Why do people use information technology? A critical review of the technology acceptance model. Information \& Management, 40(3), 191-204.

Liaw, S. S., \& Huang, H. M. (2003). An investigation of user attitudes toward search engines as an information retrieval tool. Computers in human behavior,19(6), 751-765.

Liaw, S. S. (2004). Considerations for developing constructivist web-based learning. International Journal of Instructional Media, 31, 309-319.

Park, S. Y. (2009). An analysis of the technology acceptance model in understanding university students' behavioral intention to use e-learning. Educational Technology \& Society, 12(3), 150162.

Rose, G., \& Straub, D. (1998). Predicting general IT use: Applying TAM to the Arabic world. Journal of Global Information Management (JGIM), 6(3), 39-46.

Stettheimer, T. D., \& Cleveland, A. D. (1998). Modeling utilization of planned information technology. In Proceedings of the AMIA Symposium (p. 290). American Medical Informatics Association.

Thong, J. Y., Hong, W., \& Tam, K. Y. (2002). Understanding user acceptance of digital libraries: what are the roles of interface characteristics, organizational context, and individual differences?. International Journal of Human-Computer Studies, 57(3), 215-242.

Venkatesh, V., \& Brown, S. A. (2001). A longitudinal investigation of personal computers in homes: adoption determinants and emerging challenges. MIS quarterly, 71-102. 